\title{
ON THE ROLE OF VALUE SYSTEMS AND RECIPROCITY IN COLLABORATIVE ENVIRONMENTS
}

\author{
António Abreu, L.M. Camarinha-Matos \\ New University of Lisbon \\ Quinta da Torre - 2829 Monte Caparica, PORTUGAL \\ ajfa@fct.unl.pt. cam@uninova.pt
}

\begin{abstract}
The establishment of a common value system is an important element for the sustainability of collaborative networks. This paper discusses the role of value systems in the VO breeding environment when the promotion of the cooperation is based on reciprocity mechanism. Some scenarios are included in the discussion and illustrations are given based on data from real networks.
\end{abstract}

\section{INTRODUCTION}

The behavior of an individual, society, or collaborative networked organization (CNO) is determined by the underlying value system. It is intuitively understood that the values considered in a business-oriented CNO (e.g. network of companies) are different from the ones in a non-profit context (e.g. disaster rescue network). Taking the simplified view that the goal of a CNO is the maximization of some "attribute" of its value system, in a business context the dominant value is the profit (in economic sense), while in the other case the objectives are altruist and the rewards expressed in terms of the amount of prestige or social recognition.

In general, the structure of a value system, and therefore the drivers of the CNO behavior, includes multiple variables / aspects. Complementarily there are other elements that strongly influence or determine the behavior of the CNO and its members, such as the schema of incentives, trust building and management, ethical code, the CNO culture, and the contracts and collaboration agreements.

On the other hand, it is commonly assumed the participation in a collaboration process brings benefits to the involved entities. These benefits include an increase of the "survival capability" in a context of market turbulence, but also the possibility to better achieve common goals. On the basis of these expectations are, among others, the following factors: sharing of risks and resources, joining of complementary skills and capacities, acquisition of a (virtual) higher dimension, access to new / wider markets and new knowledge, etc.

However, with the evolution of collaborative forms, the emergence of new roles, new actors and the continuous and repetitive interactions among partners make that the value generated by a collaboration process is no more determined only by its tangible assets (given by products/services supplied), but also by its intangible assets (e.g. relationship value, or "social capital"). Furthermore, in this new context the 
value system "borders" (or what characterizes the value system) are becoming less defined and its centre of gravity is changing place (Figure 1).

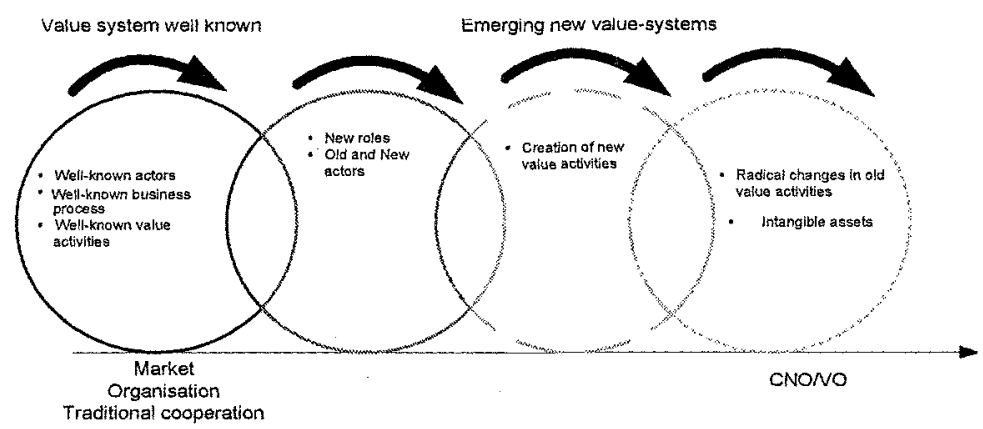

Figure 1-Evolving nature of value systems

The purpose of this paper is to discuss the value system role in the VBE context when the promotion of the cooperation is based on reciprocity mechanism.

\section{VALUE SYSTEMS}

What is a value system? A value system frequently understood as the ordering and prioritization of a set of values that an actor or a society of actors holds. However, the values that a group or an actor holds may fall into several different categories since the concept of value is multifaceted. In literature we can find several definitions for the meaning of value, two main focuses for these definitions are referred to as economic values and ethical / ideological values:

\section{Economic Value:}

- An amount, as of goods, services, or money, considered to be a fair and suitable equivalent for something else; a fair price or return. What a customer gets in exchange for the price it pays.

- To make a judgment as to the worth of something, in the sense of appraise, assay, assess, calculate, estimate, evaluate, gauge, judge.

\section{Socio- Ethical value:}

- Ethical values are those values that serve to distinguish between good and bad, right and wrong, and moral and immoral. At a societal level, these values frequently form a basis for what is permitted and what is prohibited.

- Ideological values deal with the broader or more abstract areas of politics, religion, economics, and social morals.

A number of characteristics can be considered for the values in a value system:

- Subjective - For an identical context, distinct members may apply different values and might have different perceptions of a value.

- Personal vs, social - The personal values can be applied only to one member (e.g. assets, capacity, and price) and social values can be applied to a set of members (e.g. ethical code, cooperation agreements and contracts). 
- Normative vs. Exchange - The purpose of normative values is to define a set of rules ("rights/duties") that contribute to assure the stability and the cohesion of the group since they transmit norms in a persuasive way and present an unquestionable form (e.g. trust, ethical code, and law). The purpose of exchange values is to "measure" the objects exchanged among partners in a certain context and moment.

- Dynamic - The values can change along the time. They can fade out, increase their worth or can appear for the first time.

- Measurable - The values can be measured using a quantitative or a quantitative scale.

The concept of a value system in a CNO context must be based on the notion that each product/service requires a set of value activities that are performed by a number of the network members forming a "value creation system" through a VO (this definition includes economic and ethical / ideological value as well). As a result, a value system is important in terms of providing a:

- Regulation role - for instance, regulation role can include assuring social cohesion, to understand members' behavior and to build performance indicator.

- Transactions mechanism between partners - such as, assuring an equality utility between objects exchanged.

\section{MECHANISM FOR EVOLUTION OF COOPERATION}

How to promote a cooperative behavior in a sustainable way? Several principles and mechanisms have been suggested in the literature, as illustrated in Table 1.

Table 1-Cooperation mechanisms

\begin{tabular}{|c|l|}
\hline $\begin{array}{c}\text { Cooperation } \\
\text { mechanism }\end{array}$ & \multicolumn{1}{c|}{ Short description } \\
\hline Direct reciprocity & $\begin{array}{l}\text { This mechanism suggests that actors should reciprocate help those } \\
\text { that have intentionally helped them in the past. This model can } \\
\text { explain social phenomena like for instance the live-and-let-live } \\
\text { system in trench warfare in World War I, friendships, gratitude, } \\
\text { sympathy, trustworthiness and in general all social dilemmas. In } \\
\text { the biological field it can explain the symbioses mechanism. } \\
\text { The mathematical model of cooperation via direct reciprocity is } \\
\text { based on game theory and much of the work developed applies the } \\
\text { prisoner's dilemma, stag hunt and chicken game metaphor } \\
{[2][9][14]}\end{array}$ \\
\hline Indirect & $\begin{array}{l}\text { This mechanism suggest that an actor should provide help if the } \\
\text { recipient has helped others in the past. In this mechanism it is a } \\
\text { common practice in human societies like for instance: social } \\
\text { welfare principle, insurance principle, where the donor does not } \\
\text { obtain a return from the recipient, but from a third party [1][13]. }\end{array}$ \\
\hline Kin selection & $\begin{array}{l}\text { Kin selection leads to the concept that an individual should } \\
\text { sacrifice itself in order to save "two siblings, four nephews or eight } \\
\text { cousins". Kin selection has been used to explain the evolution of } \\
\text { humanity's social structure, social insects such as ants and termites } \\
{[11][12] .}\end{array}$ \\
\hline
\end{tabular}




\begin{tabular}{|l|l|}
\hline Group selection & $\begin{array}{l}\text { This mechanism describes the process by which groups develop } \\
\text { adaptive traits that improve their fitness in their environment } \\
\text { compared to other groups. According to this approach the selection } \\
\text { mechanism can operate not only at the individual level, but also at } \\
\text { the group level where it is possible to explain the existence of } \\
\text { altruistic behaviours. Altruists may be less fit than non-altruists } \\
\text { within a single group, but groups of altruists are more fitted than } \\
\text { groups of non-altruists. } \\
\text { An approach similar to this process was the propaganda campaigns } \\
\text { in the Great Depression "We're all in it together". According to } \\
\text { social psychological, humans form coalitions on the basis of } \\
\text { virtually any commonality of interest and all humans are in the "in- } \\
\text { group" where the information "in-group" members is processed in } \\
\text { more favourable ways than information about out-group members } \\
\text { [10]. }\end{array}$ \\
\hline According to this approach individuals learn the most dominant \\
behaviours in their embedded social network. Based on this \\
principle cooperation can evolve based on cultural transmission. \\
The common metaphor, when a group of actors decide to solve \\
problems that none of the actors alone could solve, leads to \\
scenarios where cooperative behaviour is created among many \\
individuals without conscious control are cooperation examples via \\
social learning [4][15]
\end{tabular}

\section{RECIPROCITY AS A MECHANISM FOR PROMOTING COLLABORATION IN A VBE CONTEXT}

In the following discussion a VO breeding environment (VBE) is assumed as the target context [6][7]. A VBE represents an association or pool of organizations and their related supporting institutions that have both the potential and the will to cooperate with each other through the establishment of a "base" long-term cooperation agreement. When a business opportunity is identified by one member (acting as a broker), a subset of these organizations can be selected and thus forming a VO. A breeding environment, being a long-term networked structure, provide the basis to record data about past collaboration occurrences, presents the adequate base environment for the establishment of cooperation agreements, common infrastructures, common ontologies, and mutual trust, which are the necessary facilitating elements when building a new VO.

Let us consider Task Benefits (TB) as the benefits that result from the performance of a task in the context of a collaborative process. A collaborative process is understood as a set of tasks performed by the collaborative network members towards the achievement of a common goal (e.g. the business goal that motivates the creation of a Virtual Enterprise). For reasons of simplicity we consider a level of granularity of tasks such that each task is performed by a single member of the network (single actor).

In this discussion benefits are assumed as abstract quantifiable measurements with the same meaning as net profit. 
Let $t_{l j}$ be a task $t_{l}$ performed by an actor $a_{j}$ and $T B_{j i}\left(t_{l j}\right)$ the benefits for another actor $a_{i}$ as a result of the performance of this task.

When $i \neq j$ this represents a received benefit (RB) (perspective of actor $a_{i}$ ) or a contributed benefit (CB) (perspective of actor $a_{j}$ ) (Fig. 2); otherwise it is a selfbenefit, case that will not be considered in this discussion.

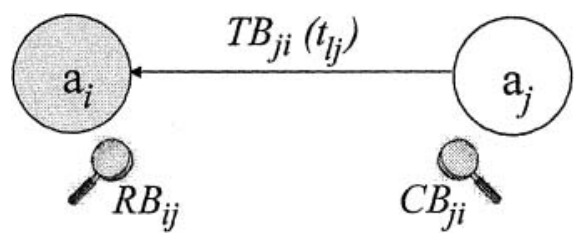

Figure 2 - Actor $a_{i}$ receives benefits from the action of actor $a_{j}$

Based on this representation (see, [5] [6] for more details), a reciprocity mechanism can be implemented by analysing the balance between "social" benefits credit (the sum of benefits contributed by an actor $a_{j}$ to all its partners) and "social" benefits debit (the sum of benefits received by an actor $a_{j}$ as a result of the performance of all actors involved in the collaborative process). The reciprocity value $\left(R_{j}\right)$ for an actor $a_{j}$ is given by:

$$
R_{j}=\sum_{i=1}^{N} C B_{j i}-\sum_{i=1}^{N} R B_{i j} \quad i \neq j
$$

Where: $\mathrm{N}$ - Number of actors involved in the collaborative process

$C B_{j i}$ - Benefits contributed by $a_{j}$ to $a_{i}$

$R B_{i j}$ - Benefits received by $a_{j}$ from $a_{i}$

When $R_{j}<0$, the actor $a_{j}$ may be seen, by its partners, as having a potentially "selfish" behaviour in the period of time in analyse, in the sense that it received more benefits than it contributed. If this balance remains negative in the long term, the actor would most likely be considered selfish and probably not an appreciated partner. On the other hand, when $R_{j}>0$, the actor $a_{j}$ might be seen, by its partners, as having a potentially "altruistic" behaviour and it would be considered altruist if it holds this behaviour in the long term.

In order to discuss the role of the value systems when the promotion of cooperation is based on a reciprocity mechanism, let us consider the following two scenarios.

\section{Scenario $1-A V B E$ with a common value system}

Let us again suppose the actor $a_{j}$ performs a task that benefits actor $a_{i}$. From the perspective of actor $a_{j}$, this action is perceived as an investment (contributed benefit 
(CB)) in actor $a_{i}$. If the two actors share the same value system then they will have the same perception of the benefit value. Based on this premise actor $a_{i}$ will valorise the benefits received $(R B)$ (its satisfaction) to the same amount ( $R B=C B$ ).

As result of actor's $a_{i}$ satisfaction, actor $a_{i}$ recognizes a "debt of gratitude" to actor $a_{j}$ (kind of social debit) and actor $a_{j}$ gets a "credit" from actor $a_{i}$. As both actors have the same perception of the benefit value then the total sum of benefits variations is null for a full cycle (Fig. 3).

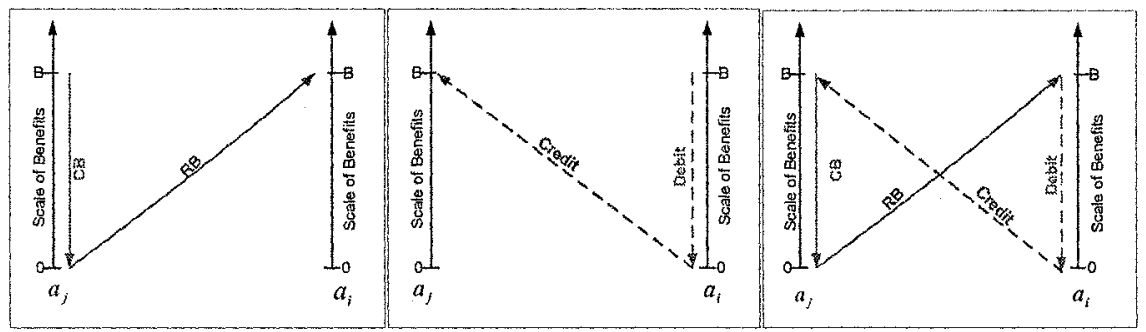

Figure 3 - Contribution of actor $a_{j}$ to actor $a_{i}$

Later on, let us suppose actor $a_{j}$ needs something done to him by others. As actor $a_{j}$ has a social credit from a past exchange he can now expect, from the reciprocity principle, to get some service from the actor $a_{i}$ (direct reciprocity) or from any other actor member of VBE (indirect reciprocity).

The assumption here is that sharing a common value system leads the two actors to perceive the value of a benefit in the same way. In this context the principle of reciprocity can be a good general governance rule for promoting collaboration. In order to illustrate this idea let us consider the following example.

\section{Example 1-Time Bank Case}

The Time Bank concept induces mutually helping communities whose value system consists of only one variable that is the quantity of time exchanged among people. The cooperation benefit is measured as the number of hours that one person spends helping another. One key principle here is that one hour is equal to everybody. One hour of helping out with gardening is equal to an hour of baby-sitting. As an illustration, Fig. 4 shows some exchanges of services among members in a Portuguese Time Bank agency.

The reciprocity principle is applied in the Time Bank in the following way: people "deposit" time they when they contribute to the community by giving practical help and support to someone; in exchange they are able to "withdraw" time when they need something done to themselves by others. 


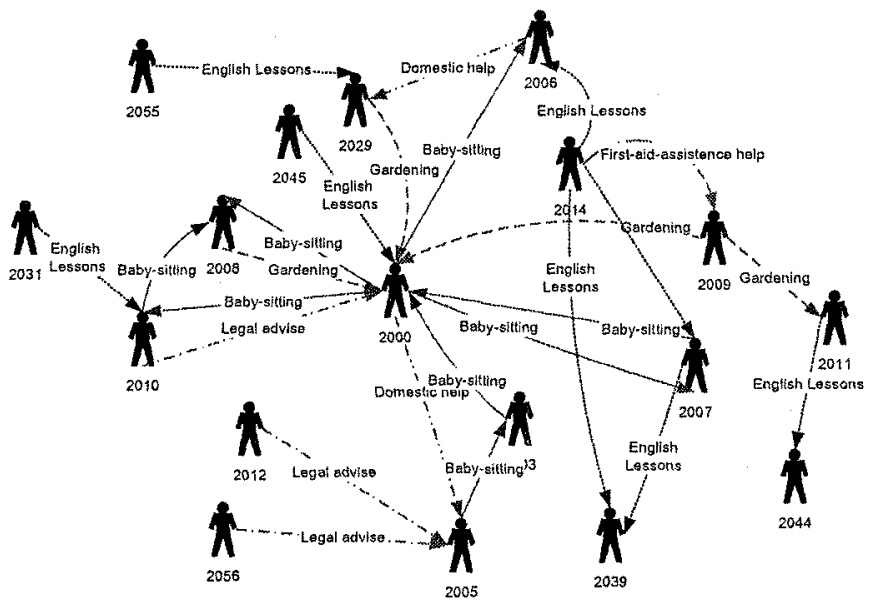

Figure 4 - Exchanges of services in a time bank agency

Based on real data from a Portuguese Time Bank agency, Fig. 5 (using UCINET [3]) shows the evolution of collaboration from the perspective of contributed benefits along two consecutive years. The nodes' size represents the level of contribution of each actor and the link's width represents the value of benefit supplied. Analysing the two graphs at the same time we can verify that in 2002 there are two nodes (2000 and 2014) that are the major contributors. When we look at 2003 the situation changed; in that year there are more big contributors and the number of links also increased, showing that a stronger cooperation level was achieved.

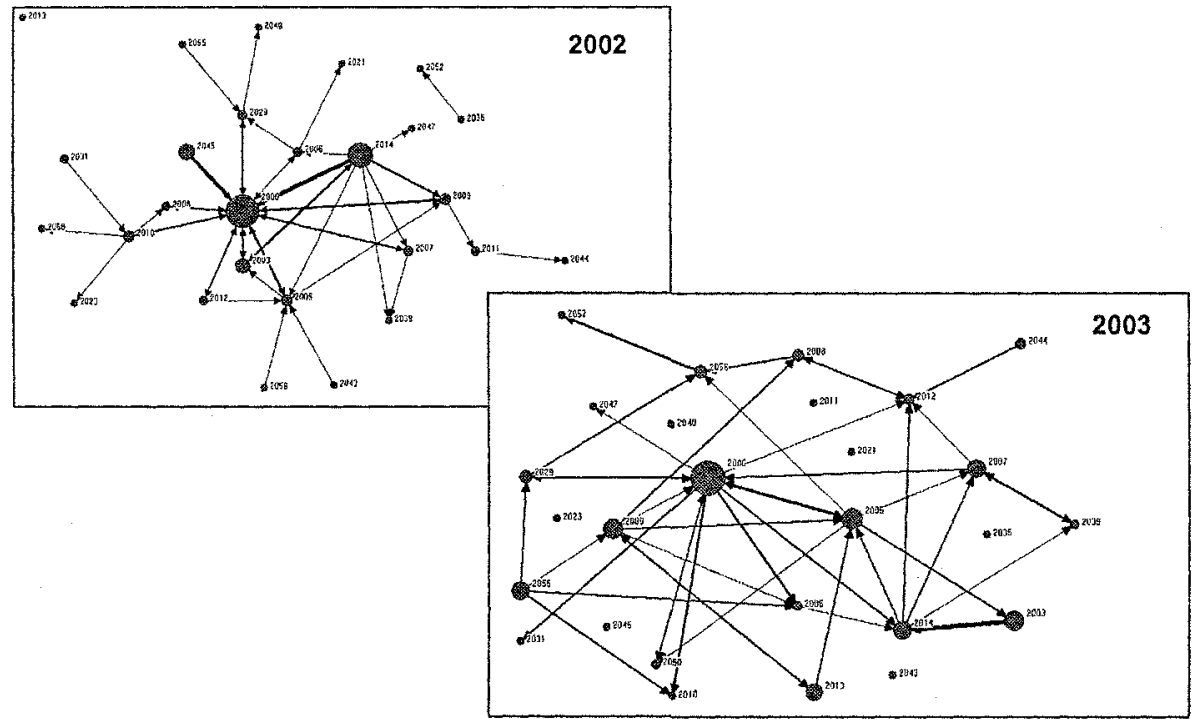

Figure 5-CB over time

This increase in the level of cooperation, and the proliferation of time banks in many countries, depends in our opinion, among others factors (such as the leadership of 
the time bank promoter), on the existence of this simple and common value system and the application of the principle of reciprocity (mostly indirect reciprocity in this case).

Scenario 2-AVBE without a common value system

Let us now discuss a scenario where actors involved in an exchange have distinct perceptions of the value of a benefit. Fig. 6 illustrates a case of benefits "depreciation", i.e. when an actor undervalues the benefits of an action performed by another. As illustrated, actor $a_{i}$ performs a task that benefits actor $a_{j}$. From the perspective of actor $a_{i}$ this action means an investment in (contributed benefit (CB) to) actor $a_{j}$. However, actor $a_{j}$ gives it a lower value and therefore the "social" credit received by the performer is less than what it assumed to be its contribution $(\mathrm{RB}<\mathrm{CB})$. This difference in perception of a value is likely to create a sense of unfairness and to reduce the will to cooperate.

We could also consider the opposite situation (less common?), as illustrated by figure 8 that represents a case of additional gain to actor $a_{i}$. In this case, from the perspective of actor $a_{i}$, the outcome of this social interaction means an additional gain because for him the level of benefits contributed to actor $a_{j}$ is lower than the level of satisfaction actor $a_{j}$ got $(\mathrm{RB}>\mathrm{CB})$. Since actor's $a_{i}$ contribution (CB) is lower than the "social" credit received from actor $a_{j}(\mathrm{CB}<$ Credit), it is likely that actor $a_{i}$ will be motivated to keep cooperating with actor $a_{j}$.

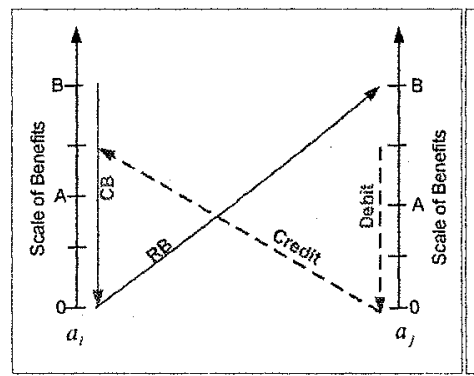

Figure 6 - Actor $a_{j}$ depreciates benefits received from the action of actor $a_{i}$

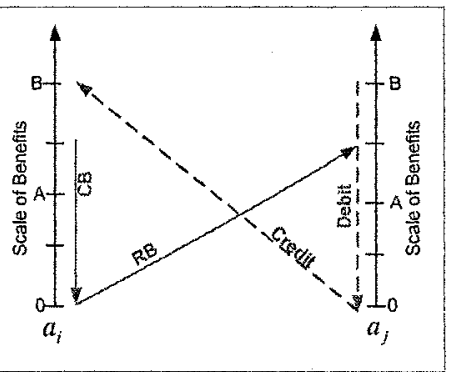

Figure 7 - Actor $a_{j}$ over appreciates the

benefits received from the action of actor $a_{i}$

Figures 8 and 9 illustrate what happens between two actors when both depreciate or both over appreciate the benefits received from the action performed by the other. In the case of figure 8 , since the level of satisfaction (perceived received benefits (RB)) is higher than the value of benefits contributed, the cooperation process is likely to stay stable over time in spite of not having a common value system as there is a mutual perception of additional gain for both actors. On the other hand, when the level of satisfaction (perceived received benefits (RB)) is lower than the value of benefits contributed, the willingness to cooperate is likely to be in danger, at least in the long term. 


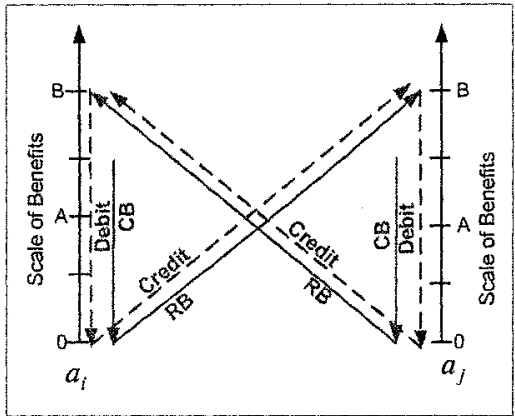

Figure 8-Reciprocal over-appreciation of received benefits

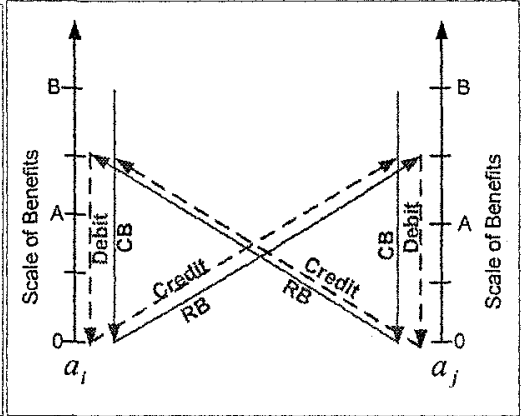

Figure 9-Reciprocal depreciation of received benefits

As discussed above, the lack of a common value system, namely in case of depreciation of benefit value, is likely to be an obstacle for the sustainability of a collaborative network. One possible approach to remedy this situation is to elaborate a number of measurable indicators and making them explicitly "visible" to all partners. In this way transparency is promoted and hopefully will contribute to a convergence towards alignment of the different perceptions of value.

The development of graphical tools that allow the visualization of some indicators of collaboration [6] for all actors at the same time could be a good approach to increase the transparency among distinct partners and in that way contribute to building-up a common value system, thus assuring the network cohesion and simultaneously the feeling of fairness inside the VBE based on indicators that measure the quality and level of collaboration of each member in public way. As an illustration, let us consider the following example.

\section{Example 2-VBE of small and medium enterprises}

This example uses input data based on Virtuelle Fabrik, a long term collaborative network (a VBE) in the metal-mechanic sector, located in Switzerland and Germany. For the purpose of the following discussion, let us consider the benefits are based only on one variable, the turnover of collaborative actions.

Based on the turnover data for 2004, the nodes' size in Fig. 10A represents the sum of benefits received, by each member, from the network and the link's width represents the value of the benefit supplied by one member to another. Hence, in this case who received more benefits were enterprises 10,11 and 13.

On the other hand, the nodes' size in Fig. 10B represents the sum of benefits contributed by an actor to the network and the link's width represents the value of the benefit supplied to a specific actor. Hence, the major contributors are enterprises 16 and 58. If we look to the links between enterprises we can casily identify, for instance, a strong exchange of benefits between enterprises 16 and 13 .

Analyzing the two graphs at the same time, we can conclude that for this period of time (one year) there are some enterprises, for instance enterprise 58, which might feel "uncomfortable" with its participation on this VBE. In fact, if the situation of enterprise 58 holds for a long time, its participation in this collaborative network could become unsustainable in the long term as it might consider that there is no reciprocity. 

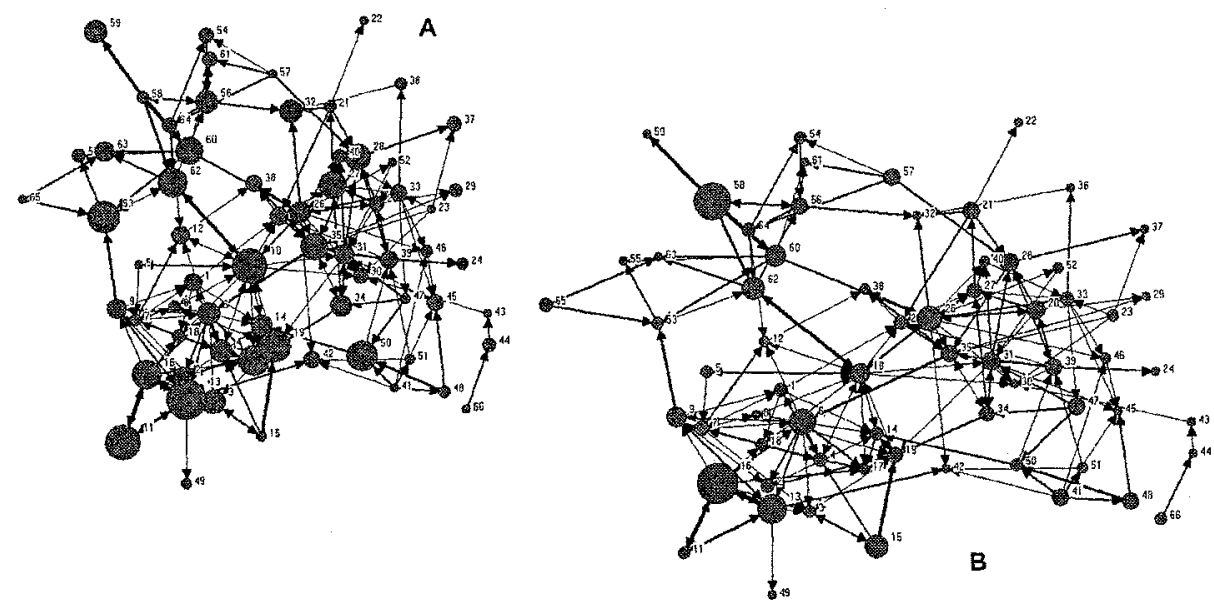

Figure 10-Received benefits (A) and contributed benefits (B) for 2004

The graph in Fig. 11A shows the benefits credit balance $\left(R_{j}>0\right)$ for all enterprises members of the VBE. Based on the period of time under consideration the enterprises 15,16 and 58 exhibit a potential altruistic behavior in the sense that they contributed much more benefits than they received.

On the other hand, Fig. 11B shows the benefits debit balance $\left(R_{j}<0\right)$ for all enterprises members of the VBE. For the considered period of time, enterprises 11 , 50,53 and 59 exhibit a potentially "selfish" behavior in the sense that they received much more benefits than they contributed, or at least this can be the perception got by the other partners looking at these indicators.
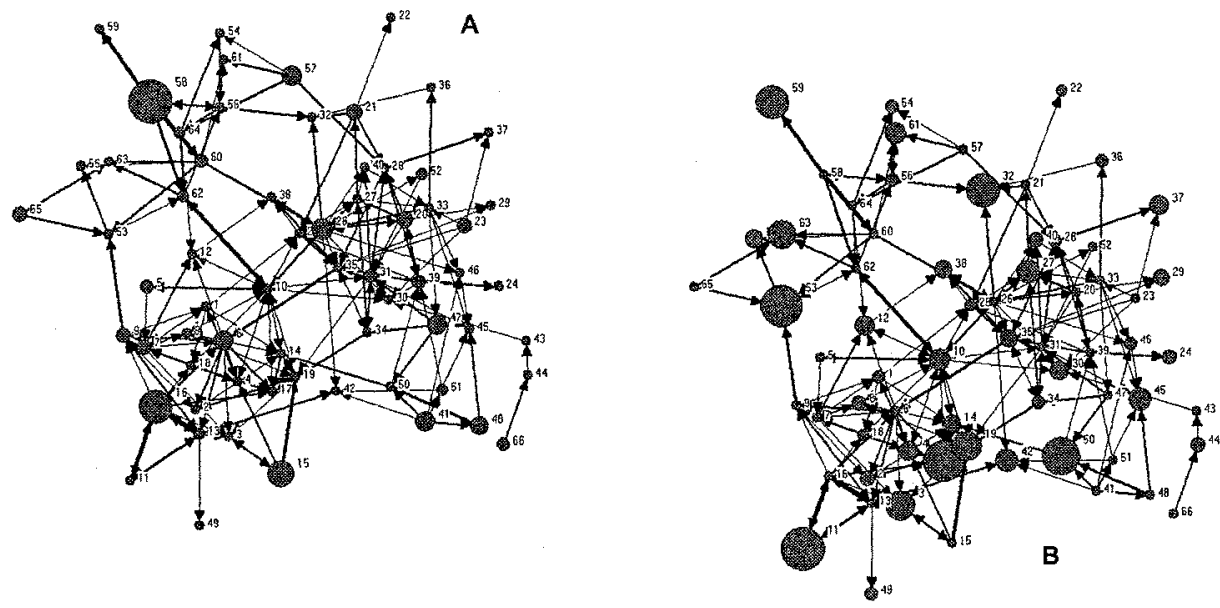

Figure 11 - Benefits credit (A) and debit (B) for 2004

In rational terms the motivation for a company to stay in the VBE should be based on a comparison of the benefits it gets versus what it could get if working alone out of this community. Nevertheless it is also important to consider the natural tendency 
of people to make comparisons with their partners and therefore it is very important to avoid the emergence of any feeling of unfairness.

In order to reduce the problems discussed above it is necessary to implement mechanisms that act as incentives for cooperation. For instance, honorific recognitions, higher chances to get access to business opportunities, more access to some assets and even punishment of "selfish" behaviors (e.g. less access to opportunities, higher cost in the access to common services/assets). Perhaps one challenge is to create, at the VBE level, a kind of indicator of the level of cooperation that lets members accumulate and use "credits" in a similar way as in the Time Bank.

For instance, in the social network analysis area there is an indicator of "prestige" of a member in a network. Applying this concept here, Fig. 12 relates actors' prestige to the sum of received benefits. Although in a broad sense it could make sense that the total of received benefits (RB) would grow with prestige, in the sense that actors that are more prestigious tend to receive more external benefits links, we can notice that for the same level of prestige different companies got quite different levels of benefits.

Different reasons can be considered for this situation, for instance: the amount of benefits an actor receives depends on several other factors belonging to the value system that were not taken into account in this example. Therefore, although explicit representations of the "status" of collaboration according to some indicators can increase the transparency of the network, it might also have a negative effect if the set of indicators is not properly defined and a good set of indicators is not introduced in the governance principles of the VBE.

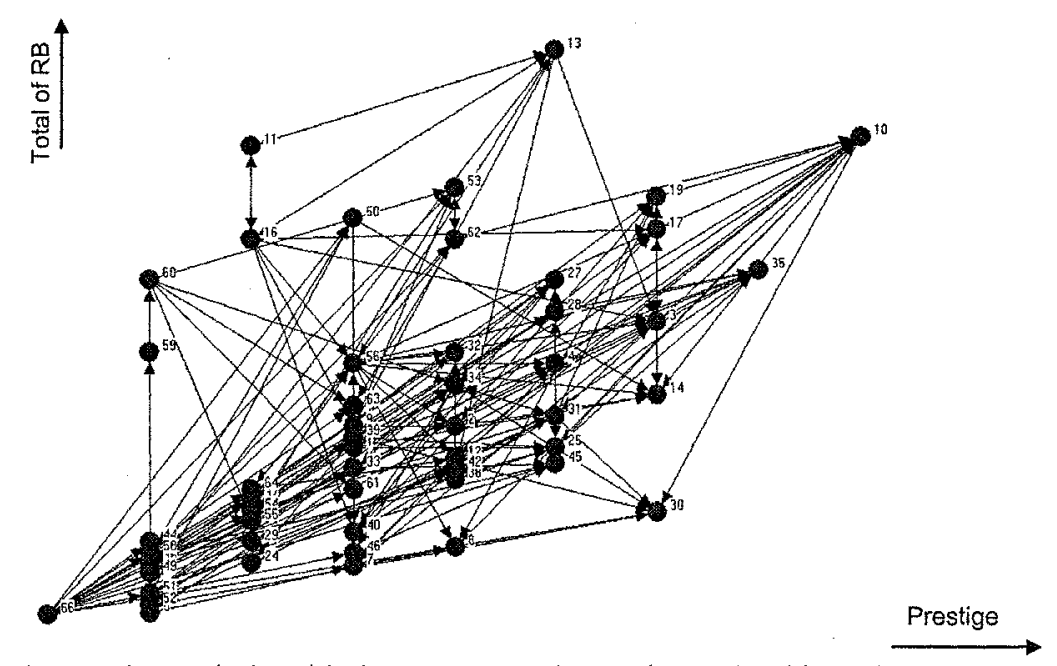

Figure 12 - Relationship between Prestige and Received benefits for 2004

\section{CONCLUSIONS}

The development of a common value system in a VBE context is an important step 
to support the sustainability of collaborative behavior over the time. When partners have different value systems, which typically leads to different perceptions of benefits, non-collaborative behaviors are likely to develop. In order to overcome this problem, some mechanisms to promote transparency and induce alignment of value systems might be implemented at the level of the governance rules of the VBE. A discussion of approaches in this direction, illustrated by a simple "value-set" case based on transactions values, was presented.

However, more work is necessary in order to identify a proper set of indicators of the collaboration level of each partner.

Acknowledgments - This work was supported in part by the ECOLEAD integrated project funded by the European Commission. The authors thank Stefan Bollhalter (Virtuelle Fabrik) for the help with example data.

\section{REFERENCES}

1. Alexander, R. D. (1987). The Biology of Moral Systems, Aldine.

2. Axelroad, R. (1984). The Evolution of Cooperation, Basic Books.

3. Borgatti, S.P., Everett, M.G. and Freeman, L.C. 2002. Ucinet for Windows: Software for Social Network Analysis. Harvard, MA: Analytic Technologies.

4. Boyd, R., and Richerson, P. J. (1982). Cultural transmission and the evolution of cooperative behaviour. Human Ecology, 10, 325-351.

5. Camarinha-Matos, L. M.; Abreu, António (2004). A contribution to understand collaborative benefits - Emerging solutions for future manufacturing systems, Springer, ISBN 0-387-22828-4.

6. Camarinha-Matos, L. M.; Abreu, António (2004). Performance indicators based on collaboration benefits- Collaborative Networks and their Breeding Environments, Springer, ISBN 0-387-28259-9.

7. Camarinha-Matos, L. M.; Afsarmanesh, H. (2003). Elements of a VE base infrastructure, J. Computers in Industry, Vol. 51, Issue 2, Jun 2003, pp. 139-163.

8. Camarinha-Matos, L. M; Afsarmanesh, H. (Ed.s) (2004). Collaborative Networked Organizations - A research agenda for emerging business models, Kluwer Academic Publishers, ISBN 1-4020-7823-4.

9. Ernst, F., and Simon, G. (2000). Fairness and Retaliation: The Economics of Reciprocity. Journal of Economic Perspectives, 14, 159-181.

10. Eshel, I. (1972). On the neighbour effect and the evolution of altruistic traits. Theoretical Population Biology, 3, 258-77.

11. Hamilton, W. D. (1963). The evolution of altruistic behaviour. The American Naturalist, 97, 354-356.

12. Hamilton, W. D. (1964). The genetic evolution of social behaviour. Journal Theoretical Biology, 7, 1-52.

13. Nowak, M., and Sigmund, K. (1998). Evolution of Indirect Reciprocity by Image Scoring. Nature, 393, 573-577.

14. Roberts, G., and Sherratt, T. N. (1998). Development of cooperative relationships through increasing investment. Nature, 394, 175-179.

15. Simon, H. A. (1991). Organizations and markets. Journal of Economic Perspectives, 5, $25-44$ 